\title{
Organizações internacionais não-governamentais no sistema de governança global: a ICAN e o tratado sobre a proibição de armas nucleares
}

\author{
PEDRO Diniz RochA*
}

Artigo recebido: 30 de maio de 2019

Artigo aprovado: 10 de fevereiro de 2020

Doi: https://doi.org/10.12804/revistas.urosario.edu.co/desafios/a.7936

Para citar este artigo: Rocha, P. D. (2020). Organizações internacionais não-governamentais no sistema de governança global: a ICAN e o tratado sobre a proibição de armas nucleares. Desafíos, 32(2), 1-32. https://doi.org/10.12804/revistas.urosario.edu.co/desafios/a.7936

\section{Resumo}

O objetivo geral deste artigo éo de demonstrar o processo pelo qual uma Organização Internacional Não-Governamental (OING) a partir do processo de enquadramento de uma questão na agenda internacional foi capaz de influenciar resultados em uma Organização Internacional. Em especifico, buscou-se compreender o papel desempenbado pela ICAN (em inglês, International Campaign to Abolish Nuclear Weapons) na aprovação do Tratado sobre a Proibição de Armas Nucleares (TPAN) pela Assembleia Geral das Nações Unidas em 17 de julho de 2017. De modo a cumpri-lo, em termos metodológicos adotou-se o process-tracing, tendo o mecanismo causal sido construído e guiado a partir do arcabonco teórico proposto por Jutta Joachim (2007). Ao fim e ao cabo, se espera contribuir para a literatura em Relações Internacionais

\footnotetext{
* Universidade Estadual Paulista (UnesP), Instituto de Políticas Públicas e Relações Internacionais, Programa de Pós-Graduação em Relações Internacionais Santiago Dantas (UNESP - UNICAMP - PUC/SP), Brasil. Correio eletrônico: pedro.diniz.rocha@gmail.com. ORCID: https://orcid.org/0000-0002-1365-3292
} 
ao propor estudo centrado nos processos de negociação em meio ao sistema de governança global, especificamente no que concerne ao papel das OINGs e sua interrelação com outros atores de relevância internacional.

Palavras-chave: governança global; armas nucleares; Organização Internacional Não-Governamental; International Campaign to Abolish Nuclear Weapons; Tratado sobre a Proibição de Armas Nucleares; controle de armas.

\title{
International non-Governmental Organizations at the Global Governance System: ICAN and the Treaty on the Prohibition of Nuclear Weapons
}

\begin{abstract}
This article demonstrates how an international non-governmental organization may influence results in an international organization through the initial framing of an issue. Specifically, it aims to understand the role of ICAN (International Campaign to Abolish Nuclear Weapons) in the approval of the Treaty on the Probibition of Nuclear Weapons (TPNW) by the United Nations General Assembly on July 17, 2017. Methodologically, it is based on process-tracing, with causal mechanisms being constructed based on the theoretical framework proposed by Jutta Joachim (2007). The article is expected to contribute to the literature by proposing to focus on the negotiating process within the international governance system, specifically concerning the role of INGOs and their interrelation with other relevant actors in the global arena.

Keywords: Global Governance; nuclear weapons; international non-governmental organization; International Campaign to Abolish Nuclear Weapons; Treaty on the Probibition of Nuclear Weapons; arms control.
\end{abstract}




\title{
Organizaciones no gubernamentales internacionales en el sistema de gobernanza global: ICAN y el tratado sobre la prohibición de las armas nucleares
}

\begin{abstract}
Resumen
El objetivo general de este articulo es demostrar el proceso por el cual una Organización Internacional No Gubernamental (OING), a partir del proceso de desarrollo de una pregunta marco en la agenda internacional fue capaz de influenciar resultados en una Organización Internacional. Especificamente, se buscó comprender el papel desempeñado por la ICAN (en inglés International Campaign to Abolish Nuclear Weapons) en la aprobación del Tratado sobre Probibición de Armas Nucleares (TPAN) por la Asamblea General de las Naciones Unidas el 17 de julio de 2017. Siendo este el objetivo, en términos metodológicos, se adoptó el process-tracing, habiendo sido el mecanismo causal construido y guiado a partir del marco teórico propuesto por Jutta Joachim (2007). Finalmente, se espera contribuir a la literatura en Relaciones Internacionales al proponer un estudio centrado en los procesos de negociación en medio del sistema de gobernanza global, especificamente, en lo que concierne al papel de las OING y su interrelación con otros actores de relevancia internacional.

Palabras clave: Gobernanza global; armas nucleares; Organización Internacional No Gubernamental; International Campaign to Abolish Nuclear Weapons; Tratado sobre Probibición de Armas Nucleares; control de armas.
\end{abstract}

\section{Introdução}

Em meio as últimas décadas as Organizações Internacionais Não-Governamentais (OINGs) vem se firmando como componentes relevantes do sistema de governança global ao lado de atores tradicionais como Estados e Organizações Internacionais (OI). Se em 1948, por exemplo, o Conselho Econômico e Social (ECOSOC) das Nações Unidas (ONU) reconhecia somente 48 OINGs, hoje mais de 11000 já estão a ele associadas e ativamente buscam influenciar resultados em âmbito internacional (ECOSOC, 2019). O que se reflete na academia onde o fenômeno ganha cada vez mais espaço e é abordado a partir de distintas perspectivas teóricas e epistemológicas, como se observa no 
recente Routledge Handbook of NGOs and International Relations (2019), organizado por Thomas Davies.

Nesse sentido, o objetivo geral deste artigo é o de demonstrar o processo pelo qual a ICAN (em inglês, International Campaign to Abolish Nuclear Weapons) a partir do enquadramento da questão nuclear em termos humanitários foi capaz de influenciar resultados de negociação em uma organização internacional e impulsionar a aprovação do tratado sobre a Proibição de Armas Nucleares em meio a Assembleia Geral das Nações Unidas (AGNU). O que significa, portanto, que não será discutida a efetividade em si do tratado como instrumento do direito internacional, até porque, até o momento, ele ainda não está em vigor havendo somente $35^{1}$ das 50 ratificações necessárias para tanto. Dito isto, se parte da seguinte pergunta: qual foi o papel desempenhado pela ICAN na aprovação do Tratado sobre a Proibição de Armamentos Nucleares (TPAN) pela AGNU em 17 de julho de 2017?

A hipótese do artigo é a de que a ICAN entre 2010 e 2012 passa a enquadrar a questão nuclear em termos humanitários. Desde aquele momento passa então a acumular parceiros internacionais —lideranças globais, comunidades epistêmicas, outras ONGs, Estados, dentre outros-e ganha acesso à arena internacional, onde se aproveita de divergências históricas sobre a questão para colocá-la em pauta e influenciar o rumo das discussões dentro das Nações Unidas. Outrossim, mobiliza sua estrutura e faz lobby pela aprovação do TPAN, o que acontece em 7 de julho de 2017 apesar da oposição de todos os Estados Nuclearmente Armados, da OTAN e de países extra-OTAN, como Austrália e Japão, dentre outros. De modo a testá-la, será realizado estudo de caso a partir de process-tracing guiado pelo arcabouço teórico proposto por Jutta Joachim (2007) em Agenda Setting, NGOs and the UN.

Espera-se contribuir para a literatura em Relações Internacionais ao propor estudo centrado nos processos de negociação em meio ao sistema de governança global, especificamente no que concerne ao papel

1 Situação do tratado em 27 de janeiro de 2020. 
das Organizações Não-Governamentais e sua interrelação com outros atores de relevância internacional. Em específico, ao apresentar estudo de caso guiado pelo argumento de Joachim (2007) em questão-área diferente da original, o artigo pode também servir de teste importante para o modelo. Caso a hipótese seja comprovada, o modelo sai fortalecido; em caso contrário, ele sairá enfraquecido substancialmente.

O texto segue em duas seções, para além desta introdução e das considerações finais: na primeira seção, será apresentado o arcabouço teórico responsável por guiar as discussões e pequeno desenho de pesquisa a ser empregado neste artigo; por fim, na segunda seção, será conduzido o estudo de caso onde se buscará descortinar o papel desempenhado pela ICAN na aprovação do Tratado sobre a Proibição de Armamentos Nucleares (TPAN).

\section{As organizações não governamentais em meio ao sistema de governança global}

Parte-se do pressuposto que a governança global é um processo eminentemente político e não somente um conjunto de normas e regras que regem a atividade humana, como proposto por autores como Roseneau (1995). Isto é, a governança global é concebida como aquela interação social entre atores de um sistema internacional tendo em vista a resolução de seus conflitos de interesse de forma pacífica. Incorpora todo um conjunto de atividades direcionadas à tomada de uma decisão coletiva e é, portanto, um processo dinâmico estando o arranjo do sistema de governança global em constante transformação desde a interação política daqueles capazes de influenciar e implementar o seu resultado ${ }^{2}$ (Avant et al., 2010; Willets, 2011; Weiss, 2013). Aqueles capazes de influenciar e implementar o resultado das

\footnotetext{
2 Acredita-se que esta abordagem de governança global é interessante, na medida em que nos permite olhar de maneira mais crítica para a maneira pela qual o sistema de regras e normas que compõe a estrutura de governança global foi formado pela interação política entre os governantes globais, e a forma pela qual ele se transforma ao longo do tempo. O que está de acordo com abordagens como a de Weiss e Wilkinson (2014), onde os autores apontam para a necessidade de capturar em meio às discussões sobre governança global,
} 


\section{6 / Pedro Diniz Rocha}

decisões coletivas em âmbito internacional são os governantes globais(em inglês, global governors) descritos por Avant et al. (2010). Identificar quem são os governantes globais importa, na medida em que são esses os agentes capazes de "criar questões, estabelecer agendas, implementar as regras e avaliar ou adjudicar as consequências” de conflitos de interesse no sistema internacional (Avant et al., 2010, p. 2).

Organizações Internacionais Não-Governamentais (OINGs) são aqui definidas como qualquer organização não-estatal, não-criminosa, não-violenta e sem fins lucrativos que opera para além das fronteiras de um único país (Davies, 2014; 2019). É central para este artigo o entendimento de que bem como Estados e Organizações Internacionais (OIS), as OINGs também podem ser concebidas como governantes globais; isto é, como capazes de influenciar e implementar o resultado das decisões coletivas de âmbito internacional (Avant et al., 2010). Neste sentido, Drezner (2007) separa a ação das OINGs com impacto no sistema de governança global em duas esferas: advocacia e serviços. Apesar do reconhecimento de ambos os domínios de atuação, o objetivo deste artigo é compreender a maneira pela qual OINGs buscam alterar estruturas de governança global; isto é, suas atividades no âmbito da advocacia. A diferença de outros governantes globais como Estados e OIs, o argumento é o de que o fazem com certo grau de efetividade mesmo sem a capacidade de criar por si só qualquer tipo de quadro legal ou possuir recursos materiais suficientes para compelir de forma coercitiva a ação de outrem em âmbito internacional (Drezner, 2007). Se entende ser isto possível, na medida em que as OINGs possuem conjunto intenso e coerente de preferências e conhecimento especializado que lhes são fonte de autoridade, assim como flexibilidade de ação pela ausência de constrangimentos burocráticos que lhes dá certa autonomia na ação política (Drezner, 2007; Willets, 2011).

$\mathrm{Na}$ política internacional as questões e a agenda não existem e não são determinadas de forma rígida e natural, mas são produzidas ativamente 
pelos governadores globais desde sua interação. A criação e o posicionamento de uma questão na agenda, portanto, é o primeiro passo adotado pelas OINGs com o objetivo de transformar a estrutura de governança internacional (Porta \& Tarrow, 2005). Isto se dá desde um processo de enquadramento onde as OINGs chamam à atenção situações e/ou eventos particulares, influenciando a maneira pela qual outros atores no sistema as percebem, identificam, interpretam e tomam decisões alocativas (Keck \& Sikkink, 1998; Porta \& Tarrow, 2005; Allan \& Hadden, 2017). O objetivo é transformar a saliência das questões de acordo com suas próprias preferências para o maior número de atores possíveis, de modo a garantir resultados políticos que se adequem a seus interesses.

O processo de enquadramento contém três fases inter-relacionadas: (i) diagnóstico, (ii) solução e (iii) politização. Na primeira fase, as OINGs identificam no mundo situações e enredos que vão contra as ideias e valores que lhes deram origem e colocam em risco a concretização de seus interesses e preferências. Neste processo, destacam suas causas e suas consequências de modo a atrair atenção e encorajar ação em relação à questão (Keck \& Sikkink, 1998). Na segunda fase, as OINGs desenvolvem soluções dentro de seu sistema de ideias e valores que atacam as causas e previnem as consequências dos problemas identificados, além de garantirem resultado compatível com seus interesses e preferências. Por fim, na terceira fase, as OINGs buscam de forma estratégica convencer outros governadores globais, particularmente Estados e seu eleitorado, de que seu diagnóstico está correto e que a solução proposta é a maximizadora (Joachim, 2007).

O enquadramento apesar de necessário, não é suficiente para afetar resultados na política internacional. Isto porque os problemas, as soluções e os motivos introduzidos pelas OINGs são frequentemente contrários aos interesses e às preferências de outros governadores globais e acentuam as divergências de interesse sobre as questões em pauta (Joachim, 2007). Alguns atores se recusam a enxergar o problema diagnosticado pelas OINGs como um problema de fato e preferem o status quo à mudanças significativas na estrutura de governança global (Avant et al., 2010). A efetividade das atividades de advocacia das OINGS 
iniciadas pelo processo de enquadramento de uma questão tende, portanto, a variar significativamente. De acordo com Joachim (2007) tal variação pode ser explicada a partir de duas variáveis: a estrutura de oportunidade dentro do sistema ao qual determinada OING se integra e a estrutura de mobilização que ela possui à disposição.

A estrutura de oportunidade se refere às dimensões do ambiente político as quais as OINGs estão integradas que podem tanto impor constrangimentos, quanto proporcionar oportunidades para o exercício de suas atividades e, portanto, impactam em sua capacidade de promover mudanças na estrutura de governança global (Joachim, 2007; Thiel \& Uçarer, 2014). Joachim (2007) identifica três aspectos centrais que compõe a estrutura de oportunidade das OINGs: (i) o acesso a órgãos decisórios internacionais, (ii) a presença de aliados em meio aos demais governadores globais; (iii) a existência de alinhamentos políticos contrários e de divergência percebida de interesses entre os Estados (Joachim, 2007).

Em primeiro lugar, acesso aos órgãos decisórios internacionais significa não somente espaço e tempo nas arenas formais de tomada de decisão, mas também possibilidade de posicionamento nas arenas informais onde as negociatas tomam forma (Smith, 2006). Acesso às arenas formais e informais de tomada de decisão garante voz às OINGs em meio ao processo de alocação autoritária de valores e ocasião para construir credibilidade em frente aos demais governadores globais (Thiel \& Uçarer, 2014). Outrossim, o acesso possibilita angariar potenciais aliados influentes em meio ao sistema de governança global e a identificar alinhamentos políticos e conflitos entre os Estados que podem potencialmente ser explorados em meio ao processo de enquadramento (Joachim, 2007).

Em segundo lugar, a coleção de parceiros internacionais e domésticos é fundamental para o sucesso do processo de enquadramento, afinal as OINGs carecem por si só de recursos materiais, privilégios institucionais e capacidade de criar ou modificar normas internacionais (Joachim, 2007). Fundações como a MacArthur e a Rockefeller podem ser essenciais na providência de recursos materiais que financiem os 
seus trabalhos, Organizações Não-Governamentais domésticas são importantes para a atividade lobista e outras OINGs e comunidades epistêmicas podem dar maior credibilidade e prestígio à campanha (Joachim, 2007). Outrossim, o apoio do secretariado das Nações Unidas pode facilitar o acesso aos canais formais e informais da organização. De especial relevância é o apoio do Secretário Geral, na medida em que dada sua posição é potencializada a alavancagem dos valores, das ideias e das propostas das OINGs (Joachim, 2007).

Dentre todos os parceiros das OINGs, o apoio dos Estados talvez seja o mais crucial. Estados seguem como as principais unidades do sistema internacional, e mais do que qualquer outro ator possuem os recursos materiais, os privilégios institucionais e a capacidade de criar e modificar a estrutura de governança internacional (Weiss, 2013). Isto é, para além da garantia do capital necessário para manutenção da campanha, os Estados podem incluir representantes das OINGs em suas delegações, introduzir nos organismos decisórios internacionais resoluções e emendas embasadas em suas propostas e, para além, votar nas resoluções e emendas introduzidas (Joachim, 2007). Não obstante, apesar de todas as oportunidades, o suporte dos Estados pode também tornar-se um problema e impor constrangimentos as OINGs. Isto porque, dado o posicionamento dos Estados em meio ao sistema internacional, em geral, e à questão evidenciada, em particular, o suporte pode tanto impedir o apoio de um maior número de países, quanto se voltar contra à própria credibilidade da Organização (Joachim, 2007).

Por fim, mudança nos alinhamentos políticos e impasse entre os Estados podem criar oportunidades para a ação das OINGs. Mudanças talvez tragam em evidência blocos de Estados que compartilham os interesses e as preferências das OINGs e precisam de suporte para consolidar suas posições no cenário internacional. Impasses podem ser importantes na medida em que impedem os Estados de coordenar suas preferências e a alocar os valores de forma não-maximizadora e disforme aos interesses das Organizações, além de abrirem a oportunidade para as OINGs atuarem como bridge-builders apresentando suas propostas como uma terceira via capaz de contorná-lo. De qualquer 
maneira, o suporte de blocos de Estados particulares pode também impedir as soluções propostas pelas OINGs de se concretizarem, pois podem as atochar com agendas e interesses particulares impedindo o suporte de outros blocos. Outrossim, na medida em que as rivalidades podem ser severas a ponto de impedir os tomadores de decisão de dar atenção à novas ideias e proposições (Joachim, 2007).

Não obstante, uma estrutura de oportunidades por si só pode não ser suficiente para garantir os resultados esperados pelas OINGs. Há também que aproveitá-las a partir dos recursos disponíveis em meio a sua estrutura de mobilização, definidas como as conexões formais e informais que possibilitam a coordenação de ações coletivas. A estrutura de mobilização é composta, portanto, pelas redes de interação transnacionais constituídas pelas OINGs. Por meio delas se organizam as campanhas, potencializando o processo de enquadramento das questões e fortalecendo a própria estrutura de oportunidades (Joachim, 2007). Desde Joachim (2007), três são os principais elementos da estrutura de mobilização: (i) empreendedores organizacionais; (ii) audiência internacional; ${ }^{3}$ (iii) especialistas e vítimas (p. 32).

Em primeiro lugar empreendedores organizacionais são aquelas organizações ou indivíduos parceiros das OINGs que a partir de seu prestígio, experiência, conexões, visão e carisma podem facilitar a ação coletiva ao absorver os custos iniciais da mobilização. Eles formam uma rede de ação coletiva transnacional (Porta \& Tarrow, 2005), ou rede de advocacia transnacional (Keck \& Sikkink, 1998), responsável por promover a campanha e difundir os valores, ideias e propostas formuladas em meio ao processo de enquadramento da questão (Joachim, 2007). Em segundo lugar, fazem também parte da estrutura de mobilização indivíduos ativos nas campanhas empenhadas pelas OINGs, àqueles que contribuem com pequenas doações sazonais e outros membros anônimos da sociedade civil que de uma maneira ou outra dão suporte às ideias, valores e às propostas das organizações (Joachim, 2007). Uma audiência internacional diversa e heterogênea é

\footnotetext{
3 Em inglês, international constituency.
} 
importante para as OINGs na medida em que tanto dificulta o descrédito de suas propostas pela afirmação de que representam somente o interesse de grupos particulares, quanto auxilia e potencializa o lobby em âmbitos doméstico e internacional (Joachim, 2007).

Por fim, especialistas e vítimas são os últimos componentes da estrutura de mobilização e essenciais para a mobilização tanto de empreendedores organizacionais, quanto de uma audiência internacional heterogênea. Comunidades epistêmicas contribuem com seu conhecimento técnico e científico e aumentam a credibilidade das proposições defendidas. Isto porque podem comprovar de maneira hipoteticamente objetiva e neutra a existência de determinado problema e a potencialidade das soluções propostas pelas OINGs. Da mesma maneira, a credibilidade das proposições defendidas pode ser aumentada desde o testemunho das vítimas diretas dos problemas aos quais as OINGs se propõem a solucionar. Suas histórias eminentemente parciais e subjetivas derivadas de suas experiências personalizam a questão. Se antes obscuro e distante, o problema à vista da sociedade civil internacional e de outros governantes globais pode se tornar próximo e urgente, demandando pronta resolução (Joachim, 2007).

Tendo como ponto de partida a discussão teórica aqui delineada, construiu-se mecanismo causal que deve ser entendido como a hipótese de trabalho deste artigo (tabela 1). Entende-se por mecanismo causal como "uma série de partes interligadas que transmitem forças causais de X a Y" (Beach \& Pedersen, 2013, p. 29). Cada parte do MC é composta por entidades - e.g. pessoas - que se engajam em atividades - e.g. protestam—, sendo as atividades executadas pelas entidades, as responsáveis pela transmissão de força causal ao longo do mecanismo (Beach \& Pedersen, 2013). As partes não são aqui consideradas variáveis intervenientes já que, de fato, elas não podem variar: ou cada uma das partes está presente, ou o mecanismo como um todo não o está (Beach \& Pedersen, 2013). 
Tabela 1. Hipótese / Mecanismo Causal

\begin{tabular}{|l|l|}
\hline \multicolumn{1}{|c|}{ Partes } & \multicolumn{1}{c|}{ Entidades e Atividades } \\
\hline Parte I & A ICAN passa a enquadrar questão nuclear em moldes humanitários \\
\hline Parte II & A ICAN coleciona parceiros internacionais \\
\hline Parte III & A ICAN ganha acesso à arena internacional \\
\hline Parte IV & $\begin{array}{l}\text { A ICAN aproveita de divergências sobre a questão nuclear para } \\
\text { influenciar a discussão dentro das Nações Unidas }\end{array}$ \\
\hline Parte V & $\begin{array}{l}\text { A ICAN mobiliza suporte e faz lobby pela aprovação do Tratado sobre a } \\
\text { Proibição de Armamentos Nucleares }\end{array}$ \\
\hline Parte VI & $\begin{array}{l}\text { O Tratado sobre a Proibição de Armamentos Nucleares é aprovado na } \\
\text { Assembleia Geral das Nações Unidas }\end{array}$ \\
\hline
\end{tabular}

Fonte: elaboração própria.

Para identificar o enquadramento da questão nuclear por parte da ICAN em termos humanitários serão observados documentos oficiais produzidos pela ICAN, como seus kits de campanha e coletâneas publicadas pela organização. Acredita-se que a partir destes documentos será possível observar o seu posicionamento em relação à questão nuclear e fazer inferências relativas à seu enquadramento em termos humanitários. De modo à identificar os parceiros internacionais da ICAN serão coletados dados diretamente do site oficial da ICAN, onde há listagem explícita de seus parceiros. Em relação especificamente à Estados parceiros, serão identificadas ações concretas/práticas que incluem a ICAN de forma substantiva. Por exemplo, a Noruega foi reconhecida como parceira entre 2012 e 2015 na medida em que seu aporte financeiro foi essencial para a abertura de escritórios da organização na Europa.

De modo a inferir o acesso da ICAN à arena internacional, se buscou observar a presença formal de representantes da organização em arenas formais e informais de negociação, como, por exemplo, as conferências sobre os impactos humanitários dos armamentos nucleares. Em relação a ICAN ter aproveitado ou não as divergências sobre a questão nuclear, foi analisado desde fontes secundárias a forma pela qual a divergência é posta entre os Estados e se a OING de fato capitalizou em cima desta. Quanto à mobilização de suporte e lobby, se procurou identificar em meio à fontes primárias e secundárias ações concretas da ICAN com 
este objetivo. Por exemplo, desde Shirobokova (2018) se identificou a maneira pela qual a organização mobilizou sua estrutura, pressionando grupos populares e parlamentares, resultando na presença da Holanda nas negociações em meio às Nações Unidas. Por fim, em relação ao TPAN, sua presença foi identificada de maneira direta por documentos oficiais da ONU que atestam a aprovação do Tratado sobre a Proibição de Armas Nucleares em 17 de Julho de 2017.

\section{A ICAN e o tratado sobre a proibição de armamentos nucleares}

O surgimento e a resolução de questões é o elemento definidor da política internacional e de sua transformação (ver Randle, 1987). Deste ponto de vista, a detonação das bombas nucleares em Hiroshima e Nagasaki pelos Estados Unidos ao fim da Segunda Guerra Mundial ganha contornos importantes, já que é entendida aqui como marco do advento da questão nuclear. Desde aquele momento, uma série de iniciativas foram postas em prática tendo como objetivo a sua resolução em meio ao sistema de governança global (ver Goldblat, 2002). Estas podem ser divididas em três tipos principais: (i) propostas com o objetivo de abolir o uso de armamentos nucleares; (ii) propostas com o objetivo principal o desarmamento; e (iii) propostas com o objetivo de conter a proliferação nuclear. Nota-se que desde a formulação do Plano Baruch em 1946 até 2010 as discussões sobre a questão tiveram sua ênfase nas duas últimas maneiras (mesmo que todas as três tenham coexistido ao longo do tempo); isto é, o foco dos governantes globais se deu em alternativas que privilegiam o desarmamento e/ou a não-proliferação nuclear.

Realidade que se observa ao levarmos em conta o processo de negociação do TNP na década de 1960 e seus três pilares constitutivos: a não-proliferação, o desarmamento e o uso pacífico da energia nuclear. De maneira geral, os Estados não-nuclearmente armados (ENNA) e em especial o Movimento dos Não-Alinhados (MNA) sustentavam sua posição sobre a proposta do desarmamento, enquanto os Estados nuclearmente armados (ENA) defendiam a consecução de um arranjo 
que privilegiasse a não-proliferação (Potter \& Mukhatzhanova, 2012; Lodgaard, 2011). A solução de compromisso encontrada naquele momento foi o estabelecimento de práticas concretas voltadas à não-proliferação nuclear, tendo como contrapartida a inclusão de artigo no TNP (VI) versando sobre o prosseguimento em boa-fé das negociações para o desarmamento e a garantia por parte dos ENA da difusão de tecnologia nuclear para fins pacíficos para aqueles ENNA signatários (Ford, 2007).

Apesar do caráter discriminatório do TNP dada sua ênfase na não-proliferação, a inclusão do artigo VI indicava ser o tratado, um primeiro passo necessário para a eliminação dos armamentos nucleares e das distinções entre ENA e ENNA (Lodgaard, 2011). O que a longo prazo e em especial ao fim da guerra fria se tornou um problema, na medida em que dito artigo deixa em aberto buracos claros acerca de como prosseguir efetivamente em direção ao desarmamento (Siracusa \& Warren, 2018). Isto porque não estabeleceu práticas concretas para se atingir o objetivo, declarando somente que as partes do TNP se comprometem "a entabular, de boa-fé, negociações sobre medidas efetivas para a cessação em data próxima da corrida armamentista nuclear e para o desarmamento nuclear e sobre um tratado de desarmamento geral e completo, sob estrito e eficaz controle internacional" (Brasil, 1998). Iniciativas unilaterais e bilaterais de desarmamento foram adotadas ao longo do tempo principalmente por Estudos Unidos e União Soviética/Rússia em direção à questão. O que se observa, por exemplo, a partir dos programas SALT I e II, START I e II e SORT, dentre outros, que de fato contribuíram significativamente para a redução no número de ogivas nucleares ativas entre 1986, aproximadamente 70300 (Siracusa \& Warren, 2018, p. 23), e 2019, aproximadamente 13865 (SIPRI, 2019). No entanto, as negociações para o estabelecimento de um tratado geral e completo de desarmamento nuclear não encontraram seu espaço ou foram efetivas em meio às Conferências de Revisão do TNP.

Não obstante, o imediato pós-guerra fria foi marcado por uma conjuntura que a princípio se desenhava como favorável à concretização do desarmamento nuclear (Gibbons, 2018). Em meados de 1995, quando da Quinta Conferência de Revisão do TNP, estava na agenda 
negociações de um Tratado para o Corte de Material Físsil (FMCT) e um Tratado de Interdição Completa de Ensaios Nucleares (CTBT) (Lodgaard, 2011) e entidades da sociedade civil apresentaram à época estudos e propostas em matéria de desarmamento nuclear ${ }^{4}$ (Goldblat, 2002). Outrossim, já em 1997 os ENA emitiram nota declarando determinação para prosseguir com esforços sistemáticos e progressivos para a eliminação das armas nucleares e na Sexta Conferência de Revisão do TNP em 2000 foi adotado por consenso um plano para o desarmamento composto de 13 passos práticos, ${ }^{5}$ que foram somente estabelecidos de fato quando da Oitava Conferência de Revisão em 2010 (Gibbons, 2018; Lodgaard, 2011).

De qualquer maneira, os prognósticos em pouco tempo se revelaram incorretos. Por um lado, as negociações para o FMCT não chegaram a caminhar e já em 1999 o senado estadunidense rejeitou a ratificação do Ствт (Siracusa \& Warren, 2018). Por outro lado, os ENA pouco fizeram para implementar os 13 passos acordados por consenso em 2000 e a retórica do desarmamento se dissolveu quando do início da Sétima Conferência de Revisão em 2005 (Gibbons, 2018; Lodgaard, 2011). A conferência falhou, portanto, em chegar a qualquer resolução relativa ao problema ou recuperar os pequenos avanços obtidos desde 1995 (Ruff, 2018). A incapacidade dos Estados em progredir nas discussões sobre o desarmamento foi então o mote para os Médicos Internacionais para Prevenção de Guerras Nucleares (em inglês, IPPNW) e em particular Ronald McCoy, ex-co presidente da entidade, proporem a criação da ICAN já em 2005 (Gibbons, 2018; Ruff, 2018).

Aos moldes da ICBL (em inglês, International Campaign to Ban Landmines) e sua campanha para o banimento de minas terrestres na década de 1990, McCoy propôs a formação de uma OING guarda-chuva tendo

4 Ver, por exemplo, o Stimson Center Report, o Camberra Report, o CIS AC Study e o Tokyo Forum Report e o modelo para Convenção de Armamentos Nucleares (Goldblat, 2002).

5 Essa discussão retoma em intensidade sob a forma de roadmap para o desarmamento nuclear na Oitava Conferência de Revisão do tnp em 2010, após chamada de Ban Ki Moon, então Secretário Geral das Nações Unidas, em seu Five Point Proposal for nuclear disarmament (2008). De qualquer forma, os avanços no tema foram parcialmente prejudicados por impasse na Nona Conferência de Revisão do tnp em 2015. 
como objetivo principal a eliminação dos armamentos nucleares. A ICAN é lançada oficialmente em 2006 no Congresso Global da IPPNW em Helsinki, Finlândia, e em princípio é capitaneada e financiada na Austrália pela Associação Médica pela Prevenção da Guerra (MAPW) e a Poola Foundation, respectivamente (Gibbons, 2018; Ruff, 2018). Apesar de em novembro daquele ano já ter estabelecido escritório em Melbourne, a OING inicia seus trabalhos em âmbito internacional somente na reunião preparatória para a Oitava Conferência de Revisão do TNP realizada em 2007, em Viena (Borrie et al., 2018).

Em seus primeiros anos de formação, entretanto, a ICAN não teve como objetivo primário o tratado para o banimento de armamentos nucleares. Dentro da lógica do desarmamento e como forma de quebrar o impasse nas negociações em âmbito das Conferências de Revisão do TNP, a OING promovia a Convenção de Armamentos Nucleares introduzida em 1997 às Nações Unidas por Costa Rica e Malásia. O que se observa, por exemplo, pelo convite dos governos de Austrália e Japão para a participação de membros da ICAN na Comissão Internacional sobre Não-Proliferação Nuclear e Desarmamento. A campanha pelo Tratado de Proibição de Armamentos Nucleares começa de fato somente entre 2010 e 2012 após discurso de Jakob Kellemberger, então presidente da Cruz Vermelha, na Oitava Conferência de Revisão do TNP. Naquele momento as preferências da ICAN são parcialmente reestruturadas: se antes o foco era o desarmamento, se passa a advogar pela abolição do uso (Borrie et al., 2018).

\section{Parte I: a ICAN passa a enquadrar a questão nuclear em moldes humanitários.}

O advento de fato da campanha humanitária em meio a questão nuclear se origina, portanto, somente na Oitava Conferência de Revisão do TNP em 2010 (Gibbons, 2018; Potter, 2017). Movidos pelo discurso de Kellemberger representando a Cruz Vermelha, os Estados incluíram no documento final da reunião parágrafo onde "expressam preocupação acerca das consequências humanitárias do uso de armamentos nucleares" (ONU, 2010, \$80). Ainda uma OING jovem em busca de afirmação a ICAN capitaliza sua campanha nestes 
moldes, internalizando novo discurso e modificando suas preferências relativas à questão nuclear. O que se potencializa em 2012 pela decisão da Noruega de financiar seus trabalhos e de convocar no ano seguinte com a ajuda da ICAN uma conferência internacional sobre o tema (Borrie et al., 2018).

O objetivo da Iniciativa Humanitária ${ }^{6}$ é transformar o discurso ao redor da questão nuclear (Hanson, 2018). Acredita-se que a linguagem em termos de segurança internacional voltada aos benefícios da dissuasão nuclear impediu desde 1968 o cumprimento do artigo VI do TNP. Isto porque colocou em evidência os interesses dos Estados, marginalizando o impacto civil e humano de uma tragédia nuclear (Bolton \& Minor, 2016). O que se argumenta ter contribuído para o impasse político, na medida em que mesmo àqueles defensores do desarmamento o fazem em termos nacionalistas tendo como base o contraste entre a equidade soberana dos Estados e o viés discriminatório do TNP. Se parte, portanto, de um argumento societário onde a questão é problematizada tendo como referencial a humanidade como um todo. O que potencialmente contribui para solucionar o impasse na medida em que os custos e benefícios das armas nucleares passam a ser calculados desde a lógica da segurança humana (Bolton \& Minor, 2016; Ruzicka, 2018).

A argumentação tem como base a combinação de elementos morais e legais. Em termos morais, a rejeição dos armamentos nucleares se justifica pela ênfase nas consequências universais e catastróficas de seu uso para a humanidade. Por esse ângulo, se reitera o impacto indiscriminado e de longo prazo na sociedade humana, sendo capaz de atingir uma miríade de esferas para além do efeito imediato da detonação (Bolton \& Minor, 2016; Ruzicka, 2018). Em termos legais, o argumento é o de que armamentos nucleares ferem o direito humanitário, já que não fazem distinção entre combatentes e civis e suas repercussões vão além

\footnotetext{
6 A Iniciativa Humanitária é um grupo de Estados formado em 2010 às margens das reuniões de revisão do TNP com o objetivo de deslocar as discussões relativas à questão nuclear para uma perspectiva com foco na segurança humana e nos impactos humanitários das armas nucleares (Nielsen, 2019).
} 
de qualquer sentido de proporcionalidade. A Iniciativa Humanitária busca então colocar as armas nucleares na mesma categoria de outros armamentos como as bombas de fragmentação, as armas biológicas e as minas terrestres e propõe instrumento internacional responsável por banir seu uso (Ruzicka, 2018).

Desde o Kit de Campanha de 2015, é possível se perceber a maneira pela qual a ICAN internaliza as ideias e os valores da IH e contribui para sua disseminação ao enquadrar a questão nuclear em seus termos. Ali a OING atesta a necessidade de reestruturar o debate deixando de lado conceitos estreitos de segurança voltados ao Estado (ICAN, 2015). Afirmam sê-las ameaça existencial à sociedade humana, na medida em que seus efeitos são indiscriminados e catastróficos não podendo ser controlados no espaço e no tempo (ICAN, 2015). Por este ângulo, fundamentam então seu argumento na noção de segurança humana; isto é, acreditam ser a abolição do uso e a eliminação das armas nucleares uma parte importante na luta pelos direitos básicos e existenciais de todas as pessoas (ICAN, 2015).

De modo a realizar o diagnóstico, a ICAN coleta, analisa e dissemina evidências independentes do impacto humanitário do uso de armamentos nucleares (Bolton \& Minor, 2016). O que se observa na coletânea organizada em 2013 por Beatrice Fihn e publicada pela Liga Internacional das Mulheres pela Paz e Liberdade (em inglês, WILPF) em parceria com a ICAN. Ali se reuniu trabalhos específicos onde foram salientadas as consequências das armas nucleares para a saúde (Ruff, 2013), meio ambiente (Ruby, 2013), agricultura e segurança alimentar (Helfand, 2013), economia (Dumas \& Nelson, 2013) e desenvolvimento (Acheson, 2013). Outrossim, são apresentados estudos de caso sobre Hiroshima e Nagasaki (Tomonaga, 2013), as Ilhas Marshall (Johnston, 2013) e Bombay (Ramana, 2013). Estes que em conjunto com histórias reais de suas vítimas — ver, por exemplo, a história de Sumiteru Tanigushi (ICAN, 2015, p. 4)— são disseminados de forma a aproximar sua audiência e os tomadores de decisão do problema evidenciado. 
Em termos de solução, a ICAN incorpora tanto o discurso moral, quanto os elementos legais da IH como um todo. Em sua campanha, destacam estarem as armas nucleares na mesma categoria de outros armamentos inumanos na medida em que possuem uma capacidade indiscriminada de destruição e não são capazes de distinguir combatentes de não-combatentes (ICAN, 2015). Apesar disso, salientam que ao contrário de armas como as minas terrestres ou as bombas de fragmentação, as armas nucleares não possuem um instrumento internacional que as bane e estigmatize (ICAN, 2015). Propõem então a elaboração de um instrumento legal dentro do escopo do direito internacional humanitário responsável por abolir o seu uso (ICAN, 2015). De acordo com a OING o banimento representaria um primeiro passo em direção a sua eliminação, na medida em que possibilitaria estigmatização sistêmica que ao longo prazo tende a levar a sua obsolescência (ICAN, 2014).

Em sua campanha a ICAN busca a mobilização pública de sua audiência promovendo conferências, workshops, folhetagem e protestos ao redor do mundo de modo a destacar a responsabilidade individual de cada um (ICAN, 2013; ICAN, 2014). Sua estratégia principal teve dois frontes, de modo a impulsionar sua atividade lobista tanto em meio aos parlamentos nacionais, quanto em meio à AGNU: em âmbito doméstico incentivou a criação de campanhas nacionais aos seus moldes que ao atuar localmente puderam desde dentro edificar a vontade pública dos Estados pelo banimento (ICAN, 2014); em âmbito internacional, como uma organização guarda-chuva, buscou formar coalizão civil internacional entre parceiros estratégicos de modo a promover de forma coordenada o engajamento de agências do Sistema ONU e de seu secretariado (ICAN, 2014; ICAN, 2015).

\section{Parte II: a ICAN passa a colecionar parceiros internacionais.}

A ICAN se define desde a origem como uma organização guarda-chuva, sendo sua campanha composta e estruturada por uma gama de outras organizações que auxiliam na coordenação de suas atividades e na administração de seus recursos. As OINGs associadas a ICAN são divididas desde 2012 entre aquelas parte do grupo diretor internacional (ISG, em inglês International Steering Group) e as organizações parceiras 


\section{0 / Pedro Diniz Rocha}

(Borrie et al., 2018). O grupo diretor é responsável pelo "planejamento estratégico, fiscalização financeira, levantamento de recursos e formulação das políticas" (ICAN, 2018, s/p), estando em contato direto como o Diretor Executivo da organização. Outrossim, auxiliam no processo de filiação e no contato com as demais organizações parceiras. Atualmente são membros do ISG da ICAN 10 OINGs estabelecidas ao redor do mundo e influentes em suas perspectivas regiões, como a $P A X, \mathrm{o}$ Article 36, o African Council Council of Religious Leaders (ACRL), o IPPW, a WILPF, dentre outras (tabela 2.) (ICAN, 2018; ICAN, 2019a).

Para além das organizações membros do ISG, a ICAN buscou formar uma coalizão global de organizações nacionais parceiras. Estas são responsáveis pela promoção da campanha e de seus objetivos, concretizando em âmbito local ações coordenadas internacionalmente, além de executar a atividade lobista em meio aos parlamentos nacionais (ICAN, 2019a). A rede de instituições parceiras à ICAN foi fundamental para garantir o acesso da OING aos tomadores de decisão e atrair Estados à Iniciativa Humanitária, além de terem garantido maior capacidade de influência durante as negociações do Tratado sobre a Proliferação de Armamentos Nucleares (Borrie et al., 2018). Hoje a ICAN conta com a parceria de mais de 527 organizações domésticas, a maior parte estando na Europa (219), Oceania (88) e na África (69), ver tabela 3 (ICAN, 2019b).

Tabela 2. International Steering Group (ISG), ICAN

Acronym Institute for Disarmament Diplomacy
African Council of Religious Leaders - Religions for Peace
Article 36
International Physicians for the Prevention of Nuclear War
Latin America Human Security Network
Norwegian People's Aid
PAX
Peace Boat
Swedish Physicians against Nuclear Weapons
Women's International League for Peace and Freedom

Fonte: Elaborado pelo autor a partir de ICAN (2019a) 
Tabela 3. Organizações Parceiras, ICAN

Internacionais: 33
Nacionais (total): 527
Africa: 69
América do Norte: 64
América Latina e Caribe: 23
Ásia: 49
Europa: 219
Oceania: 88
Oriente Médio: 15

Fonte: ICAN (2019b). Partner Organizations

Embora a coalizão global de organizações não-governamentais promovida pela ICAN tenha sido fundamental para o sucesso de sua campanha, o seu resultado só foi possível na medida em que alguns Estados particulares atuaram como financiadores e promotores de suas propostas (Gibbons, 2018). Se destaca, por exemplo, o suporte da Noruega a Iniciativa Humanitária, no geral, e à ICAN, em particular, entre 2010 e 2015. Foram os incentivos financeiros do governo norueguês que possibilitaram em 2011 a abertura de novos escritórios da ICAN em Oslo e em Genebra e a expansão de suas atividades na África e no Oriente Médio (Gibbons, 2018; Ruff, 2018). Para além, o convite da Noruega à OING em 2012 para a organização da conferência de Oslo sobre os impactos humanitários dos armamentos nucleares foi crucial para solidificar a posição da ICAN em meio à sociedade civil internacional (Borrie et al., 2018; Gibbons, 2018). O suporte do governo norueguês, entretanto, teve seu fim em 2015 quando da derrota do Partido Trabalhista nas eleições nacionais; o que se reflete, por exemplo, tanto no voto contrário da Noruega à resolução da AGNU responsável pelo chamado ao banimento dos armamentos nucleares em 2016 (ONU, 2016a), quanto em seu não comparecimento no processo de votação do TPAN em 2017 (Borrie et al., 2018; Gibbons, 2018). 


\section{I Pedro Diniz Rocha}

Para além da Noruega, Áustria e México também tiveram papel central em absorver os custos iniciais de promoção da IH e apresentar a proposta do TPAN às Nações Unidas. Os dois países foram anfitriões das duas conseguintes conferências sobre os impactos humanitários dos armamentos nucleares realizadas em fevereiro (Nayarit) e dezembro (Viena) de 2014. Além disso, ao fim da conferência de Viena, a Áustria apresentou documento de compromisso aos esforços para estigmatização, proibição e eliminação das armas nucleares que quando do começo na $9^{a}$ Conferência de Revisão do TNP em 2015 já abarcava mais de 70 Estados (Potter, Disarmament Diplomacy and the Nuclear Ban Treaty, 2017); e o México propôs à AGNU em 2015 a abertura de novo de Grupo de Trabalho Aberto (GTA) sobre desarmamento nuclear que após três seções de negociação recomendou a negociação do que viria a ser o TPAN (Umaña, 2018).

Outrossim, se destaca também o papel dos países latino-americanos que já em meio a reunião da Comunidade de Estados Latino-Americanos e Caribenhos (CELAC) em janeiro de 2015 decidiram por unanimidade endossar o compromisso proposto pela Áustria, além de terem se colocado ativos em meio aos debates dentro do grupo de trabalho aberto proposto pelo México (Potter, 2017; Umaña, 2018). Por fim, estiveram constantemente advogando pelo tratado os Estados membros da Coalizão da Nova Agenda (CNA) formada por Egito, Irlanda, Nova Zelândia e África do Sul, para além de Brasil e México; assim como a Tailândia, que esteve na presidência do GTA em 2016 (Gibbons, 2018).

\section{Parte III: a ICAN ganha acesso à arena internacional.}

O acesso de fato da ICAN à arena internacional se deu entre 2012 e 2014, quando do convite de Noruega, México e Áustria para coordenar a participação da sociedade civil nas conferências de Oslo, Nayarit e Viena sobre o impacto humanitário dos armamentos nucleares (Ruff, 2018, p. 6). Isto porque não só posicionou a OING em meio às demais organizações não-governamentais próximas a IH propulsando, por exemplo, a formalização de seu ISG; como também facilitou os contatos da ICAN com lideranças de uma miríade de Estados 
(Borrie et al., 2018; Gibbons, 2018). Já em Oslo, a OING organizou de maneira prévia a conferência, um fórum civil contando com mais de 500 representantes de 130 ONGs de modo a difundir e criar consenso acerca da necessidade de um tratado de banimento aos armamentos nucleares (Gibbons, 2018). Outrossim, fez lobby para a participação de tomadores de decisão representantes dos Estados não nuclearmente armados no evento (Potter, 2017).

Desde Oslo, a ICAN passa a se reunir regularmente com indivíduos e organizações da sociedade civil de modo a operacionalizar as estratégias de sua campanha. Sob a direção da OING, em Nayarit (Fevereiro, 2014) a coalizão buscou influenciar a agenda, tendo como foco em especial, os impactos da detonação dos armamentos atômicos e os riscos de acidentes nucleares em seu desenvolvimento. Participaram da segunda conferência 148 Estados, sendo Índia e Paquistão os únicos ENA presentes. Ao fim dos trabalhos, o México apresenta documento convocando em tempo hábil debate visando a elaboração de um instrumento internacional aos moldes daquele proposto pela IH. O que pode ser visto como uma primeira tentativa de moldar os debates dentro da Nona Conferência de Revisão do TNP a ser realizada no ano seguinte (Gibbons, 2018; Potter, 2017).

Em dezembro do mesmo ano, a Áustria sedia em Viena a terceira conferência humanitária, dessa vez contando com a participação de 158 Estados, incluindo alguns ENA, como os Estados Unidos e o Reino Unido (Gibbons, 2018). A ICAN uma vez mais atuou de maneira ativa, coordenando a participação da sociedade civil e a convocação dos Estados para o evento. Dada a proximidade da Nona Conferência de Revisão, o tom da OING e de seus patronos sobre a necessidade de estabelecer processo diplomático em direção ao banimento cresceu. Ao fim da conferência, Michael Linhart, à época Ministro de Relações Exteriores da Áustria, apresentou documento de compromisso pelo desenvolvimento de tal instrumento internacional e convocou seus pares a assiná-lo. Quando do início da Conferência de Revisão em maio de 2015 mais de 70 Estados já o haviam assinado; o esforço, entretanto, não foi suficiente, na medida em que não havia o suporte 
dos ENA e nem dos membros da OTAN, e as decisões naquele âmbito são feitas por consenso (Gibbons, 2018; Potter, 2017).

\section{Parte IV: a ICAN aproveita de divergências sobre a questão para a colocar em pauta e influenciar a discussão dentro das Nações Unidas.}

Dentro da questão nuclear, o TNP estabelece uma divisão clara entre os direitos e os deveres dos ENA e dos ENNA, incorporando em seu artigo VI o ponto de partida para a sua solução e o fim paulatino de tal segmentação. Há, entretanto, a percepção constante de que as conversas em torno do desarmamento nuclear caminham em passos curtos e que os ENA, de fato, não pretendem em boa fé e tempo hábil estabelecer negociações sérias para lidar com a matéria (Umaña, 2018; Gibbons, 2019). Neste contexto, a campanha da ICAN passa pelo incentivo aos ENNA, a tomar o controle das discussões e a iniciar diálogos sérios acerca do banimento nuclear (e não desarmamento) com ou sem a participação dos ENA. O argumento da OING é o de que, se para desarmar é preciso do consenso daqueles que possuem armas nucleares, para banir e estigmatizar isto não seria um problema de curto prazo (Bolton \& Minor, 2016; Ruff, 2018).

Desde a primeira conferência sobre o impacto humanitário dos armamentos nucleares, de fato os ENA buscaram estabelecer narrativa contrária aquela da ICAN em meio a Iniciativa Humanitária e a boicotar de forma sucessiva tanto as conferências de Oslo, Nayarit e Viena, quanto as conseguintes negociações em âmbito das Nações Unidas (Borrie et al., 2018). O que levou ao não consenso em meio a Nona Conferência de Revisão do TNP e contribuiu para a recepção do discurso de dissonância proferido pela ICAN (Potter, 2017). A partir de 2015 havia ficado mais ou menos claro que dada a postura rígida dos ENA, o lócus do debate para o estabelecimento de um instrumento internacional sobre o banimento deveria ser não mais as Conferências de Revisão do TNP, mas a AGNU. Isto porque ali os ENNA poderiam por maioria qualificada aprová-lo com ou sem a participação direta dos ENA (Ruff, 2018; Ruzicka, 2018). 
Dessa maneira, após a Nona Conferência de Revisão do TNP, o embaixador mexicano Jorge Lomonaco com o suporte dos NAC (New Agenda Coalition) e da Áustria, assume a responsabilidade de propor um grupo de trabalho sobre as consequências humanitárias dos armamentos nucleares em meio ao primeiro comitê das Nações Unidas. O que concretiza a intenção da ICAN de trazer as discussões para um ambiente onde os ENNA por si só poderiam levar a frente sua proposta sem se tornarem reféns da posição dos ENA (Potter, 2017; Ruff, 2018). Esforços que podem ser observados já em outubro de 2015 onde duas resoluções similares são aprovadas em meio a AGNU de forma a introduzir às Nações Unidas o documento de compromisso proposto pela Áustria em dezembro de 2014 e, portanto, a necessidade de naquele âmbito, estigmatizar, proibir e eliminar os armamentos nucleares (ONU, 2015a; ONU, 2015b).

Parte V: a ICAN mobiliza sua estrutura e faz lobby pela aprovação do tratado sobre a proibição de armamentos nucleares.

A partir de 2016, o GTA proposto entra em funcionamento dentro do escopo das Nações Unidas, com o objetivo de avançar as negociações em torno da produção de uma normativa internacional que possibilite a concretização de um mundo livre de armas nucleares (ONU, 2015c). Destacam-se dois pontos principais sobre os trabalhos do GTA. Em primeiro lugar, a não participação dos Estados Unidos e dos membros da OTAN, que se posicionaram contrários à proposta da $\mathrm{IH}$ e em defesa de uma abordagem gradualista para o desarmamento nuclear (Potter, 2017; Gibbons, 2018). Em segundo lugar, a participação ativa de membros da sociedade civil, ${ }^{7}$ em sua maioria vinculados a ICAN ou a alguma de suas organizações parceiras, tanto na preparação para as reuniões, influenciando a agenda, quanto nos debates, ditando o caminho e o tom das discussões (ONU, 2016b; Potter, 2017).

Em agosto de 2016 o grupo de trabalho adota relatório final recomendando a convocação de conferência de modo a dar início às negociações

\footnotetext{
O acesso da sociedade civil ao GTA havia sido garantido pela resolução A/RES/70/33 responsável por cria-lo (ONU, 2015c).
} 


\section{6 / Pedro Diniz Rocha}

que virão a dar origem ao TPAN (ONU, 2016b, §.67). Apesar da rejeição à proposta por parte dos EUA e de seus aliados, o relatório foi aprovado em votação oral não-registrada com 68 votos a favor, 22 contrários e 19 abstenções (ONU, 2016b, \.70) e sua proposta foi logo introduzida por 35 países ao primeiro comitê (ONU, 2016a). A votação no primeiro comitê foi realizada em 27 de outubro de 2016 e assim como o relatório final do GTA ela foi de pronto adotada, com 123 votos a favor, 38 contrários e 16 abstenções (Potter, 2017). Destaca-se que a resolução decide não somente convocar as negociações em 2017 (\$.8), como também garante acesso da sociedade civil ao processo (\$.10) (ONU, 2016a) nos moldes de suas atividades no GTA.

Embora difícil de se medir em termos concretos a mobilização das organizações parceiras em nível doméstico, ao fim e ao cabo a participação da Holanda em meio às negociações de março, junho e julho de 2017, pode ser indício da importância das campanhas nacionais. Embora dada a instrução de posicionamento expedida pela OTAN o país tenha votado de forma contrária a adoção do TPAN, a Holanda foi o único membro da Organização a participar de forma ativa das negociações (Shirobokova, 2018). Isto porque em 2015 ante ação doméstica organizada pela PAX — OING membro do grupo diretor da ICAN- em conjunto com a Cruz Vermelha e o ASN Bank, o parlamento holandês havia aprovado documento convocando o governo a dar suporte a toda e qualquer negociação de um tratado tendo em vista o banimento dos armamentos nucleares (Shirobokova, 2018).

Em âmbito internacional, a participação da ICAN e de suas organizações parceiras em meio às negociações se deu de maneira direta. Ruff (2018) destaca três feições principais da participação da OING: a presença nas seções de maneira formal, a possibilidade de fazer intervenções em meio aos tópicos de discussão e de submeter documentos de trabalho e a organização de eventos paralelos aos debates (p. 8). Nas reuniões de março foram organizados painéis em conjunto à sociedade civil de modo a apresentar as delegações os problemas e as soluções a serem propostas dentro do que viria a ser o TPAN (Borrie et al., 2018). Em junho e julho, os trabalhos se concentraram no processo de (re)escrita, leitura e discussão do rascunho em uma dinâmica que se balanceava 
em reuniões formais e informais, abrindo espaço para a atividade lobista que em si é de difícil mensuração (Borrie et al., 2018). Antes de cada sessão, as lideranças da ICAN se encontravam para coordenar e planejar a atuação em meio às discussões (Gibbons, 2018) e durante as discussões seus representantes tiveram a oportunidade de comentar e propor revisões ao texto do tratado (Borrie et al., 2018).

\section{Parte VI: o tratado sobre a proibição de armamentos nucleares é aprovado na assembleia geral das Nações Unidas.}

Em 7 de julho de 2017 após quase três meses de negociações com participação ativa da sociedade civil o TPAN é adotado com 122 votos a favor, um voto contrário (Holanda) e uma abstenção (Singapura). Se destaca a não participação em meio às negociações e ao processo de votação de nenhum ENA ou membro da OTAN, com exceção da Holanda. Pela primeira vez em mais de 20 anos a ONU tornou-se fórum de negociação da questão nuclear, o que representa em grande parte os esforços da ICAN em retirar das Conferências de Revisão do TNP a responsabilidade de elaboração de um tratado tendo em vista o banimento dos armamentos nucleares. Percebe-se a passagem para a AGNU como fundamental à sua aprovação, na medida em que no novo lócus as decisões não são tomadas por consenso (Gibbons, 2018; Ruff, 2018). Enfim, o tratado é histórico em substância e a entrega do Nobel da Paz à ICAN em 2017 é por si representativo da influência de sua campanha e da IH como um todo em meio à questão nuclear desde meados de 2012.

\section{Considerações Finais}

Este artigo teve como objetivo central desvendar o processo pelo qual uma Organização Internacional Não-Governamental (a ICAN) a partir do processo de enquadramento de uma questão na agenda internacional (a abolição dos armamentos nucleares) foi capaz de influenciar resultados em uma Organização Internacional (a aprovação do tratado sobre a Proibição das Armas Nucleares em meio à AGNU). De modo a cumpri-lo, foi realizado teste no mecanismo causal 
construído tendo como base o arcabouço teórico proposto por Jutta Joachim em Agenda Setting, NGOs and the UN (2007).

Os resultados encontrados são considerados satisfatórios, pois de fato no caso estudado encontrou-se empiricamente evidências para a existência de cada um dos passos hipotetizados previamente. Isto significa que há indícios de que o mecanismo causal delineado pode explicar o advento do resultado esperado e, portanto, que o processo de enquadramento da questão nuclear em termos humanitários iniciado entre 2010 e 2012 pela ICAN foi efetivo e influenciou de maneira significativa resultados em âmbito da governança global. Mesmo sem possuir a capacidade de criar por si só qualquer tipo de quadro legal ou possuir recursos materiais suficientes para compelir de forma coercitiva a ação de outrem em âmbito internacional, a ICAN soube aproveitar de sua estrutura de oportunidade e de sua estrutura de mobilização para garantir um resultado mais próximo de seus interesses e preferências em torno da questão nuclear.

Acredita-se que o teste realizado possa ter contribuído para o fortalecimento do modelo proposto por Joachim (2007) acerca da influência de OINGs no sistema de governança global, na medida em que a hipótese/mecanismo causal construída o tendo como base foi (i) satisfatória (ii) mesmo quando adotada em questão área diferente da original. Outrossim, se salienta que dado seu objetivo o enfoque do artigo foi posto nas ações da ICAN durante o processo de negociação do tratado e, portanto, não foi discutido seus potenciais e limites como instrumento do direito internacional. Isto é, nota-se desde aqui unicamente o esforço da OING e de suas organizações parceiras no processo de enquadramento da questão nuclear em termos humanitários, logrando a aprovação do TPAN em julho de 2017.

\section{Referências}

Acheson, R. (2013). Wider consequences: Impact on development. In B. Fihn (Ed.), Unspeakable suffering: The humanitarian impact of nuclear weapons (pp. 58-65). Genebra: WILPF. 
Allan, J., \& Hadden, J. (2017). Exploring the framing power of NGOs in global climate politics. Environmental Politics, 26(4), 600-620. https:// doi.org/10.1080/09644016.2017.1319017

Avant, D., Finnemore, M., \& Sell, S. (2010). Who Governs the Globe? Cambridge: Cambridge University Press.

Beach, D., \& Pedersen, B. (2013). Process-Tracing Methods: Foundations and Guidelines. Ann Harbor: University of Michigan Press.

Bolton, M., \& Minor, E. (2016). The Discursive Turn Arrives in Turtle Bay: The International Campaign to Abolish Nuclear Weapons' Operationalization of Critical IR Theories. Global Policy, 7(3), 385-395. https:// doi.org/10.1111/1758-5899.12343

Borrie, J., Spies, M., \& Wan, W. (2018). Obstacles to understanding the emergence and significance of the treaty on the prohibition of nuclear weapons. Global Change, Peace \& Security, 30(2), 95-119. https://doi. org/10.1080/14781158.2018.1467394

Brasil (1998). Decreto n.2864 de 7 de dezembro de 1998. Brasília, DF: Presidência da República. http://www.planalto.gov.br/ccivil_03/decreto/d2864. htm $>$.Acesso em 16 mai. 2019

Davies, T. (2014). NGOs: A New History of Transnational Civil Society. Oxford: Oxford University Press.

Davies, T. (2019). Introducing NGOs and International Relations. In T. Davies (Ed.), Routledge Handbook of NGOs and International Relations (pp.1-16). New York: Routledge.

Drezner, D. (2007). All Politics Is Global: Explaining International Regulatory Regimes. Princeton: Princeton University Press.

Dumas, L., \& Nelson, T. (2013). Estimating the economic consequences of a nuclear explosion: Critical factors. In B. Fihn (Ed.), Unspeakable suffering: The humanitarian impact of nuclear weapons (pp. 50-57). Genebra: WILPF. Ecosoc (2019). Integrated Civil Society Organizations System. https:// esango. un.org/civilsociety/login.do. Acesso em: 30 mai. 2019

Ford, C. (2007). Debating Disarmament: Interpreting Article VI of the Treaty on the Non-Proliferation of Nuclear Weapons. The Nonproliferation Review, 14(3), 401-428. https:/ / doi.org/10.1080/10736700701611720

Gibbons, R. (2018). The humanitarian turn in nuclear disarmament and the Treaty on the Prohibition of Nuclear Weapons. The Nonproliferation Review, 25(1-2), 11-36. https:/ / doi.org/10.1080/10736700.2018.1486960 
Gibbons, R. (2019). Addressing the Nuclear Ban Treaty. The Washington Quarterly, 42(1), 27-40. https://doi.org/10.1080/0163660X.2019.1590080

Goldblat, J. (2002). Arms Control: The new guide to negotiations and agreements. Londres: SAGE Publications.

Hanson, M. (2018). Normalizing zero nuclear weapons: The humanitarian road to the Prohibition Treaty. Contemporary Security Policy, 39(3), 464486. https://doi.org/10.1080/13523260.2017.1421344

Helfand, I. (2013). Nuclear famine: A billion people at risk. In B. Fihn (Ed.), Unspeakable suffering: The humanitarian impact of nuclear weapons (pp. 3747). Genebra: WILPF.

International Campaign to Abolish Nuclear Weapons (ICAN) (2013). Ban Nuclear Weapons Now. http://www.icanw.org/wp-content/uploads/2012/08/ BanNuclearWeaponsNow.pdf. Acesso em 10 mai. 2019

International Campaign to Abolish Nuclear Weapons (ICAN) (2014). Campaigners Kit. http://www.icanw.org/wp-content/uploads/2012/08/ Campaigners-Kit-Pernilla_final2.pdf. Acesso em: 10 mai. 2019

International Campaign to Abolish Nuclear Weapons (ICAN) (2015). Catastrophic Human Harm. http:/ /www.icanw.org/wp-content/uploads/2012/08/ CHH-Booklet-WEB-2015.pdf. Acesso em: 10 mai. 2019

International Campaign to Abolish Nuclear Weapons (ICAN) (2018). ICAN International Structure. v.4. http://www.icanw.org/wp-content/ uploads/2018/05/ICAN-international-structure.pdf. Acesso em: 09 mai. 2019

International Campaign to Abolish Nuclear Weapons (ICAN) (2019a). Structure and People. https://www.icanw.org/campaign/structure-andpeople/.Acesso em 09 mai. 2019

International Campaign to Abolish Nuclear Weapons (ICAN) (2019b). Partner Organizations. https://www.icanw.org/campaign/partnerorganizations/. Acesso em: 09 mai. 2019

Joachim, J. (2007). Agenda Setting, NGOs and the UN: Gender, Violence and Reproductive Rights. Washington: Georgetown University Press.

Johnston, B. (2013). Nuclear weapons test, fallout, and the devastating impact on Marshall Islands environment, health and human rights. In B. Fihn (Ed.), Unspeakable suffering: The humanitarian impact of nuclear weapons (pp. 89-93). Genebra: WILPF.

Keck, M., \& Sikkink, K. (1998). Activists beyond borders: Advocacy networks in International Politics. Ithaca: Cornell University Press. 
Lodgaard, S. (2011). Nuclear Disarmament and Non-Proliferation: Towards a nuclear-weapon-free world?. New York: Routledge.

Nações Unidas (ONU) (2010). NPT/CONF.2010/50. https://undocs.org/ NPT/CONF.2010/50\%20(VOL.I). Acesso em: 20 mai. 2019

Nações Unidas (ONU) (2015a). A/C.1/70/L.37. https://undocs.org/A/ C.1/70/L.37. Acesso em: 27 mai. 2019

Nações Unidas (ONU) (2015b). A/C.1/70/L.38. https://documents-ddsny.un.org/doc/UNDOC/GEN/N15/327/13/PDF/N1532713. pdf?OpenElement. Acesso em: 27 mai. 2019

Nações Unidas (ONU) (2015c). A/RES/70/33. https://undocs.org/en/A/ RES/70/33. Acesso em: 28 mai. 2019

Nações Unidas (ONU) (2016a). A/C.1/71/L.41. https://undocs.org/A/ C.1/71/L.41. Acesso em: 23 mai. 2019

Nações Unidas (ONU) (2016b). Report of the Open-ended Working Group taking forward multilateral nuclear disarmament negotiations. https://www.unog. ch/80256EDD006B8954/(httpAssets)/B7F8C26BC8E15317C 1258018003E1D71/\$file/Final+Report+of+the+OEWG, +as+ submitted+to+GA+(clean).pdf. Acesso em: 28 mai. 2019

Nielsen, J. (2019). The Humanitarian Initiative and the Nuclear Weapons Ban Treaty. In J. Doyle (Ed.), Nuclear Safeguards, Security and Nonproliferation: Achieving security, with Technology and Policy (pp. 37-58). Oxford: Butterworth-Heinermann.

Porta, D., \& Tarrow, S. (2005). Transnational processes and social activism: An introduciton. In D. Porta \& S. Tarrow (Orgs.), Transnationalprocesses and global activism (pp. 1-17). Oxford: Rowman \& Littlefield Publishers INC.

Potter, W. (2017). Disarmament Diplomacy and the Nuclear Ban Treaty. Survival: Global Politics and Strategy, 59(4), 75-108. https://doi.org/10. 1080/00396338.2017.1349786

Potter, W., \& Mukhatzhanova, G. (2012). Nuclear Politics and the Non-Aligned Movement: Principles vs Pragmatism. Londres: Isss/Routledge.

Ramana, M. (2013). Effects of a nuclear blast over Bombay. In B. Fihn (Ed.), Unspeakable suffering: The bumanitarian impact of nuclear weapons (pp. 95-97). Genebra: WILPF.

Randle, R. (1987). Issues in the History of International Relations: The Role of Issues in the Evolution of the State System. New York: Praeger.

Rosenau, J. (1995). Governance in the Twenty-first Center. Global Governance, 1(1), 13-43. 
Ruby, F. (2013). Environmental consequences of a nuclear weapon explosion. In B. Fihn (Ed.), Unspeakable suffering: Humanitarian consequences of nuclear weapons (pp. 32-35). Genebra: WILPF.

Ruff, T. (2013). The health consequences of nuclear explosions. In B. Fihn (Ed.), Unspeakable suffering: The humanitarian impacts of nuclear weapons (pp. 15-27). Genebra: WILPF.

Ruff, T. (2018). Negotiating the UN treaty on the prohibition of nuclear weapons and the role of ICAN. Global Change, Peace \& Security, 30(2), 233-241. https://doi.org/10.1080/14781158.2018.1465908

Ruzicka, J. (2018, Online First). The next great hope: The humanitarian approach to nuclear weapons. Journal of International Political Theory, 15(3), 1-15.

Shirobokova, E. (2018). The Netherlands and the prohibition of nuclear weapons. The Nonproliferation Review, 25(1-2), 37-49. https://doi.org/ 10.1080/10736700.2018.1487600

Siracusa, J., \& Warren, A. (2018). The Nuclear Non-Proliferation Regime: An Historical Perspective. Diplomacy \& Statecraft, 29(1), 3-28. https:// doi.org/10.1080/09592296.2017.1420495

SIPRI (2019). SIPRI Yearbook 2019: Armaments, Disarmaments and International Security. Oxford: Oxford University Press.

Smith, C. (2006). Politics and Process at the United Nations: The Global Dance. Boulder: Lynne Rienner.

Thiel, M., \& Uçarer, E. (2014). Access and agenda-setting in the European Union: Advocacy NGOs in comparative perspective. Interest Groups \& Advocacy, 3(1), 99-116. https://doi.org/10.1057/iga.2014.1

Tomonaga, M. (2013). Use of atomic bomb in war: Hiroshima and Nagasaki. In B. Fihn (Ed.), Unspeakable suffering: The humanitarian impact of nuclear weapons (pp. 85-87). Genebra: WILPF.

Umaña, C. (2018). Latin America: Non-nuclear weapon states at the forefront of nuclear disarmament. Medicine, Conflict and Survival, 34(4), 295-300. https://doi.org/10.1080/13623699.2019.1574750

Weiss, T. (2013). Global Governance: What? W hy? Whither? Cambridge: Polity Press.

Weiss, T, \& Wilkson, R. (2014). Global Governance to the Rescue: Saving International Relations? Global Governance, 20(1), 19-36. https://doi. org/10.1163/19426720-02001003

Willetts, P. (2011). Non-Governmental Organizations in World Politics: The construction of global governance. New York: Routledge. 